\title{
Erratum to: A Solution of Rigid-Perfectly Plastic Deep Spherical Indentation Based on Slip-Line Theory
}

\author{
Robert L. Jackson ${ }^{1} \cdot$ Hamid Ghaednia ${ }^{1} \cdot$ Sara Pope $^{1}$
}

Published online: 19 December 2015

(c) Springer Science+Business Media New York 2015

\section{Erratum to: Tribol Lett (2015) 58: 47 DOI 10.1007/s11249-015-0524-3}

The authors would like to clarify the methodology used in this work and its limitations. The analysis is approximate because it uses the two-dimensional plane strain assumption, but the problem is axisymmetric. The axisymmetric case and the plane strain case are inherently very similar, and Tabor [1] noted how it appeared that the plane strain analysis results in a surprisingly good approximation of the axisymmetric case. However, at large indentation depths, this might be less certain as also noted by Tabor. It also appears that the slip-line equations used in the paper are very similar to Ishlinskii's work [2] and to the fully axisymmetric case as described in this work [3], which also states that strain in the circumferential direction is nil (deformations only occur on the $r-z$ plane). It should also be noted that the slip lines drawn in the paper may not be exact, but based on the analysis the most important quantity in the calculation is the total angle that the slip line bends through from the free surface to the indenter surface, regardless of its path. At a contact radius to sphere radius of 0.376, Ishlinskii found the contact pressure-to-strength ratio to be 2.61 (which may have some error due to the nature of his calculation methods). The equation in this work predicts 2.59 . The limit for small contact radii in his paper is 2.96 and 2.97 from Eq. 20. It therefore appears that the results of the current work are in agreement with his calculations. Nonetheless, Ishlinskii also stated that the pressure-to-strength ratio does not change significantly with indentation depth, which may be deceiving. Since the publication of this work, Eq. 20 has also been shown to compare well with additional finite element predictions [4].

\section{References}

1. Tabor, D.: The hardness of materials. Clarendon Press, Oxford (1951)

2. Ishlinskii, A.J.: The problem of plasticity with axial symmetry and Brinell's Test [An English Translation has been published by Ministry of Supply, A.R.D. (1947)]. J. Appl. Math. Mech. (U.S.S.R) 8, 233 (1944)

3. Chitkara, N.R., Butt, M.A.: A general numerical method of construction of axisymmetric slip-line fields. Int. J. Mech. Sci. 34(11), 833-848 (1992)

4. Ghaednia, H., Pope, S.A., Jackson, R.L., Marghitu, D.B.: A comprehensive study of the elasto-plastic contact of a sphere and a flat. Tribol. Int. 93(Part A), 78-90 (2016)
The online version of the original article can be found under doi: $10.1007 / \mathrm{s} 11249-015-0524-3$.

Robert L. Jackson

robert.jackson@eng.auburn.edu

1 Department of Mechanical Engineering, Auburn University, Auburn, AL, USA 